\title{
An Improved Ion Guide for External Ion Injection in Glow Discharge-Fourier Transform Ion Cyclotron Resonance Mass Spectrometry
}

\author{
Christopher M. Barshick \\ Analytical Chemistry Division, Oak Ridge National Laboratory, Oak Ridge, Tennessee, USA \\ John R. Eyler \\ Department of Chemistry, University of Florida, Gainesville, Florida, USA
}

To improve the existing ion transport optics of our glow discharge (GD) -Fourier transformion cyclotron resonance (FT-ICR) mass spectrometer, we simulated several ion trajectories between the GD source region and the ICR analyzer cell. These calculations suggested that a number of simple improvements, including the use of an ion flight tube and an electrically isolated conductance limit, would increase the efficiency of ion transfer through the fringing fields of the FT-ICR superconducting magnet and into the ICR analyzer cell. Ion beam intensity was monitored as a function of the distance between the GD source and the analyzer cell before and after implementing these improvements. A twentyfold improvement in the transport efficiency, as well as a fifteenfold enhancement in detected FT-ICR signals, was observed. (J Am Soc Mass Spectrom 1993, 4, 387-392)

$\mathrm{I}$ on generation external to the analyzer cell in Fourier transform-ion cyclotron resonance (FT-ICR) mass spectrometry has proved to be a powerful means of obtaining mass spectral information for ionization sources that operate above the relatively low conventional pressure requirements $\left(10^{-4}-10^{-6} \mathrm{~Pa}\right)$ necessary for high resolution and good signal-to-noise ratios. Both the dual ccll approach [1], in which ion formation takes place in a higher pressure source region adjacent to a lower pressure analyzer region, and approaches in which ions are generated external to the magnetic field and then transported through several stages of differential pumping $[2,3]$ have permitted the use of such varied sample introduction/ionization techniques as fast-atom bombardment, gas chromatography, and supersonic expansion in combination with FT-ICR mass analysis [4-6].

In a previous publication [7] we described how external injection of glow discharge (GD)-generated ions was facilitated by a relatively simple four-element electrostatic lens that accelerated and focused ions exiting the high-pressure region of the GD ion source. Other than this lens, no other acceleration, focusing, or deceleration was used. Quantitative analysis at analyte levels of $0.1 \%$ and above was demonstrated, along with mass resolution $\left(m / \Delta m_{1 / 2}\right)$ in excess of 40,000 (four times higher than any commercial GD mass spec-

Address reprint requests to John R. Eyler, Department of Chemistry, University of Florida, Gainesville, FL 32611-2046. trometer). Although the spatial distribution and energy spread of GD-generated ions is small [8], on the basis of the sensitivity demonstrated for other GD mass spectrometry instruments $[9,10]$, we believe that other factors, such as the "magnetic mirror effect" [11] or collisional scattering of ions by the relatively high gas pressures they encounter during their transport from the source, play a role in determining the total number of ions observed in the analyzer. Figure 1 illustrates the variation in magnetic field strength along the primary injection axis ( $z$-axis) for the $2.0-\mathrm{T}$ superconducting magnet used in our FT-ICR mass spectrometry system. The "rear" trap plate is defined as the plate farthest from the GD source. As the field is measured from the GD source $(1.1 \mathrm{~m}$ from the "rear" trapping plate) to the analyzer cell, an increase from 0.0095 to $2 \mathrm{~T}$ is observed. It is redsuriable to assume that the transport of ions over this region is tenuous and that our prior success can be attributed to the abundant population and small energy spread of ions exiting the GD source.

In this report, we discuss some efforts to circumvent the effects of the magnetic field on ion transport. Preliminary results are presented for an ion flight tube/decelerator combination that transports ions through the fringing fields of the magnet with minimal loss. Also addressed are the next logical steps for further increasing sensitivity, as well as the future role of GD/FT-ICR in the elemental mass spectrometry community. 


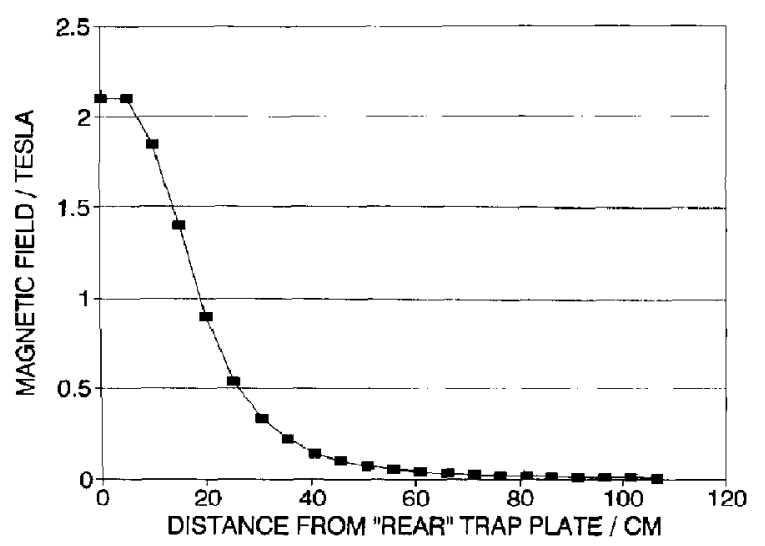

Figure 1. Magnetic field strength versus the distance from the "rear" trap plate (see text) for the 2.0-T magnet used in these studies.

\section{Experimental}

A GD/FT-ICR mass spectrometer that is capable of high-resolution elemental mass spectrometry is described in detail elsewhere [7]; however, several modifications implemented to improve ion transport are presented here. Figure 2 illustrates the orientation of the GD ion source, conductance-limiting orifice, ion flight tube, and ion decelerator with respect to an ICR analyzer cell positioned in the center of a 2.0-T superconducting magnet. One simple improvement over the previous design was the addition of an electrically isolated conductance limit (CL) containing a $1.0-\mathrm{mm}^{-}$ diameter orifice to which a variable voltage could be applied. This CL had previously been maintained at ground potential and used only to restrict gas flow from the source to the analyzer region. Additionally, an electrically isolated ion flight tube was fabricated from a 38.1-mm outside diameter (o.d.) $\times 1.6-\mathrm{mm}$ wall 304 stainless steel tube $1.0 \mathrm{~m}$ long; this tube was positioned $25.4 \mathrm{~mm}$ behind the conductance-limiting orifice along the injection $(z)$ axis. Similarly, an ion decelerator consisting of an electrically isolated ring electrode $(25.4-\mathrm{mm}$ o.d. $\times 19.1-\mathrm{mm}$ inside diameter (i.d.) $\times 2.5 \mathrm{~mm}$ long) and a grounded housing (25.4-

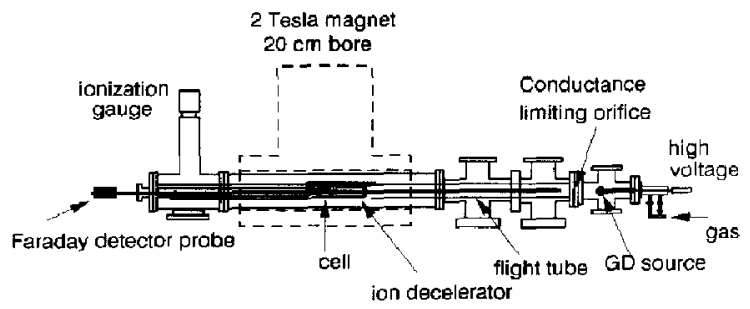

Figure 2. GD/FT-ICR mass spectrometer modified to accommodate an electrically isolated $\mathrm{CL}$, flight tube, and ion decelerator. Also shown is the Faraday cup/probe used for total ion current detection (see text). $\mathrm{mm}$ 0.d. $\times 19.1-\mathrm{mm}$ i.d. $\times 76.2 \mathrm{~mm}$ long) was machined from 304 stainless steel and positioned $12.7 \mathrm{~mm}$ from the flight tube and $2.5 \mathrm{~mm}$ in front of the entrance trapping plate of the analyzer cell. This decelerator was similar in design to that reported previously by Kofel and McMahon [12]. For these studies, two stages of differential pumping were facilitated by a $150-\mathrm{L} / \mathrm{s}$ turbomolecular pump at the ion source and two $300-\mathrm{L} / \mathrm{s}$ and one $700-\mathrm{L} / \mathrm{s}$ diffusion pumps at the analyzer (all three diffusion pumps were beyond the conductance-limiting orifice). One initial observation was that with the flight tube in place, the pressure in the high-vacuum region increased fiftyfold (from 1.33 $\times 10^{-5}$ to $6.67 \times 10^{-4} \mathrm{~Pa}$ ), owing to lower conductance with the flight tube and its supporting system. After modifying the flight tube with a series of 160 1.6-mm diameter holes along its length, it was possible to maintain an analyzer pressure of $1.33 \times 10^{-5} \mathrm{~Pa}$ while the GD source was operating at 133.3-Pa argon pressure.

An "abnormal" [8] GD used for ion formation in these studies was formed about a machined $2.0-\mathrm{mm}$ diameter pin cathode positioned on the end of a direct-insertion probe (DIP); this DIP permitted manipulation of the cathode-to-anode separation distance. The GD was operated with a constant current of 2.0 $\mathrm{mA}$ at $1500 \mathrm{~V}$ direct current (dc) and at a constant pressure of $133 \mathrm{~Pa}$ argon. The cathode-to-anode separation distance was maintained at $8.0 \mathrm{~mm}$ for all of these studies.

A total ion current detection method was developed using a Faraday cup/probe built in this laboratory. The probe was constructed from a $5-\mathrm{kV}$ high-voltage feedthrough welded into a $12.7-\mathrm{mm}$ o.d. $\times 1.6-\mathrm{mm}$ wall stainless steel tube whose total length was $2.5 \mathrm{~m}$. A $12.5-\mathrm{mm}$ diameter stainless steel Faraday cup was positioned on the end of the feedthrough, and the ion beam current was measured directly by an electrometer (Keithley model 610C, Cleveland, OH). The Faraday probe was inserted through a 12.7-mm-diameter solids insertion probe vacuum interlock to permit manipulation along the $z$ axis in the vacuum chamber. The probe passed through the ICR analyzer cell (trapping plates open) and could be extended to within a few millimeters of the cell side of the CL. In this manner, the ion beam intensity could be measured from the CL to the analyzer cell without breaking the vacuum.

When normal FT-ICR detection was needed, the probe was removed from the vacuum chamber, the grid-trapping plates were reattached to the cell, and a typical pulse sequence was used; this pulse sequence usually consisted of dropping the trapping plates from $+2 \mathrm{~V}$ to ground for a period of $0.1-5.0 \mathrm{~s}$ (to allow ions to be "injected" into the analyzer cell), followed by raising the plates back to $+2 \mathrm{~V}$ for the detection phase. No ion ejection was used for any of the studies reported here. Ions with frequencies from $10 \mathrm{kHz}$ to 2.667 $\mathrm{MHz}$ were excited and detected with a band- 
width of $2.667 \mathrm{MHz}$. In the conventional detection scheme, 50 time domain signals of $16 \mathrm{~K}$ data points each were accumulated. The average signal was apodized by a modified Blackman-Harris window function [13] and zero filled once prior to Fourier transformation. No high-resolution spectra were acquired; however, with this system it is possible to obtain up to $64 \mathrm{~K}$ data points and apply a standard heterodyne approach [14] if necessary. In this manner we previously obtained resolution $\left(m / \Delta m_{1 / 2}\right)$ in excess of 40,000 [7].

\section{Results and Discussion}

\section{Floating Conductance Limit with No Ion Flight Tube}

To evaluate the effect of the new transport optics independently of the previously used four-element lens, it was necessary to establish a set of "test" voltages under which the lens would constantly operate. For this purpose, the CL plate with the $1.0-\mathrm{mm}$ diameter orifice was replaced with an electrically isolated solid plate, and an inexpensive 2,0-mm diameter nichrome wire was used as a sample. With the CL plate at ground potential, a $2.9 \times 10^{-7}-\mathrm{A}$ ion beam current was measured on the stainless steel 30 mesh (0.28-mm wire diameter) grid, which was the first element of the lens (see Figure 3 for more detail of the lens-source configuration). Next, several voltage combinations were tried until a maximum current of $1.4 \times$ $10^{-9}$ A was measured at the CL plate; this was observed with $-825 \mathrm{~V}$ on the grid, $-898 \mathrm{~V}$ on lens 1 , $-684 \mathrm{~V}$ on lens 2 , and $-674 \mathrm{~V}$ on lens 3 . This result indicated a reduction by at least a factor of 200 in beam current in passing through the electrostatic lens. This loss was presumably due to incomplete focusing of ions exiting the GD source at large angles, neutralization of ions on the grid wires, and collisional scattering of ions by the high pressure of argon in the lens region. Variations in GD source conditions caused the absolute ion current passing through the CL to fluctuate somewhat from day to day, but the maximum current at this point never exceeded $3 \times 10^{-9} \mathrm{~A}$.

After the solid conductance plate was replaced with a 1.0-mm-diameter orifice, the ion signal was monitored by standard FT-ICR detection in the analyzer cell as a function of the $\mathrm{CL}$ voltage. Figure 4 shows that a twofold to fivefold increase in signal intensity was obtained as a negative bias was applied to the previously grounded CL. Ion signal profiles for the $\mathrm{H}_{2} \mathrm{O}^{+}$, $\mathrm{Ar}^{+}$, and $\mathrm{Ni}^{+}$species all followed similar trends, increasing sharply until approximately $-75 \mathrm{~V}$ dc was reached, followed by a slight decrease in signal intensity over the remaining range of applied voltage. This increase in signal intensity is believed to result from the more efficient transport of ions through the CL and not from any additional source of ionization.

As support for the hypothesis that the potential on

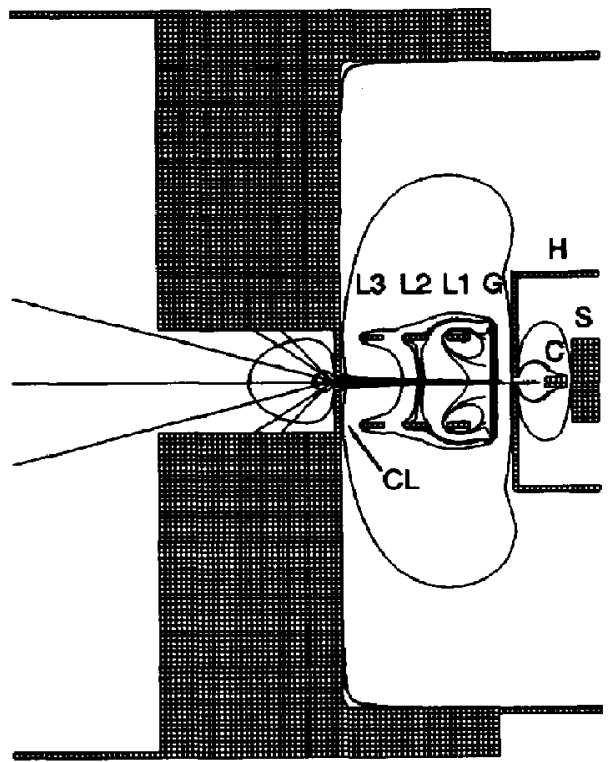

b

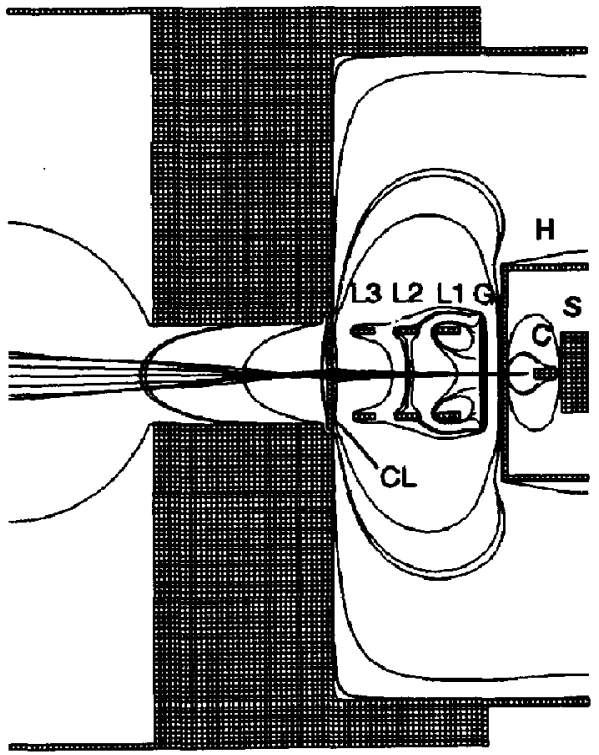

Figure 3. SIMION trajectories calculated for 13 ions with 5-eV kinetic energy under the following conditions: housing $(\mathrm{H})$, ground; source (S), ground; cathode (C), $-0.5 \mathrm{~V}$; grid (G), -825 $\mathrm{V}$; element 1 (L1), $-898 \mathrm{~V}$; element 2 (L2), $-684 \mathrm{~V}$; element 3 (L3), $-674 \mathrm{~V}$; (a) conductance limit (CL), ground; (b) conductance limit (CL), $-75 \mathrm{~V}$.

the $C L$ provided better transfer of ions from the GD source to the analyzer cell, a series of SIMION [15] trajectory calculations were performed. The initial conditions for these calculations were such that 13 ions were accelerated with $5 \mathrm{eV}$ of kinetic energy into a magnetic field gradient that varied from $9.5 \times 10^{-3} \mathrm{~T}$ at the source to $2.0 \mathrm{~T}$ at the analyzer. These ions were 
simulated to begin their trajectories $2 \mathrm{~mm}$ from a negatively biased cathode. Figure 3 illustrates these simulations for both the CL at ground potential (Figure $3 a$ ) and at $-75 \mathrm{~V}$ (Figure $3 \mathrm{~b}$ ). It is obvious from Figure 3 that the seven ions passing through the hole in a $-75 \mathrm{~V} \mathrm{CL}$ are better focused. (Six of the original 13 ions are found to strike the CL and do not pass farther in both cases.) Of note, Figure $3 a$ also predicts that only three of the 13 ions leaving the source should pass beyond the $19.1-\mathrm{mm}$ long $\times 12.7-\mathrm{mm}$ diameter opening in the grounded flange housing.

Previously, we calculated the detection limit for the nickel analyte in a National Institute for Standards and Technology (NIST) 1261a stainless steel reference material [7]. For 50 scans accumulated over a 10-100-u mass range, the standard deviation of the mean [16] of five background determinations was 15,090 counts. The ${ }^{60} \mathrm{Ni}$ isotope present at $0.52 \%$ yielded an ion signal of 3.5 million counts. Therefore the detection limit, calculated by multiplying the inverse of the sensitivity (1.5 parts per thousand/count) by three times the mean standard deviation of the background [17] was $70 \mathrm{ppm}$ [7]. With the $\mathrm{CL}$ at $-75 \mathrm{~V}$, a detection limit was again calculated for the ${ }^{60} \mathrm{Ni}^{+}$ion generated from the NIST 1261a reference material. For 50 scans accumulated over a $10-100-u$ mass range, the standard deviation of the mean was 17,020 counts. The ${ }^{60} \mathrm{Ni}$ isotope yielded an ion signal of 15.5 million counts, which corresponds to a detection limit of approximately $15 \mathrm{ppm}$, almost a factor of 5 improvement over the results obtained with the grounded $\mathrm{CL}$.

Fven though the detection limits improved with the addition of a voltage to the $C L$, no steps had yet been taken to overcome the effects of the fringing magnetic fields. To gauge those effects, the ion beam current was measured along the injection axis under our "test" conditions for both the grounded CL (Figure 5) and the $-75-V$ CL (Figure 6). Several results are seen when comparing Figures 5 and 6 . First, the signal intensity $25.4 \mathrm{~mm}$ from the CL $(1.1 \mathrm{~m}$ from the rear trapping

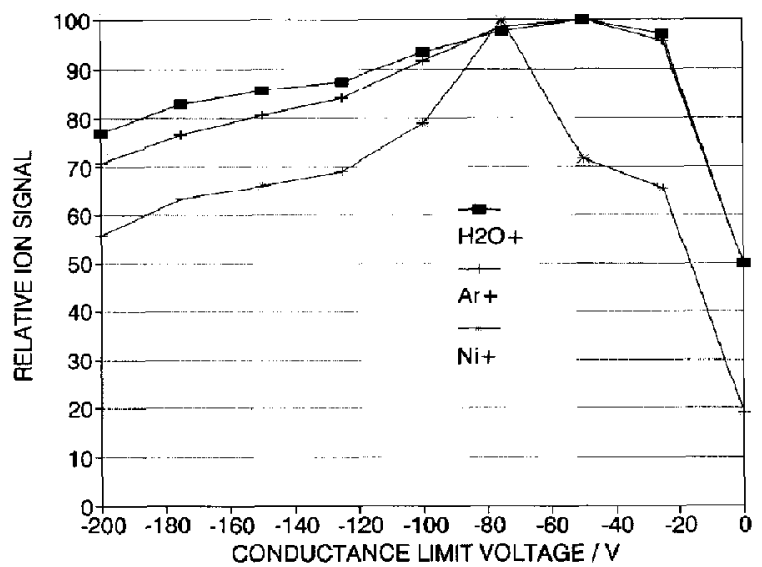

Figure 4. Relative signals for water, argon, and nickel ions versus $C L$ voltage. Other lens element voltages were grid, -825 $\mathrm{V}$; element 1, $-898 \mathrm{~V}$; element $2,-684 \mathrm{~V}$; element $3,-674 \mathrm{~V}$.

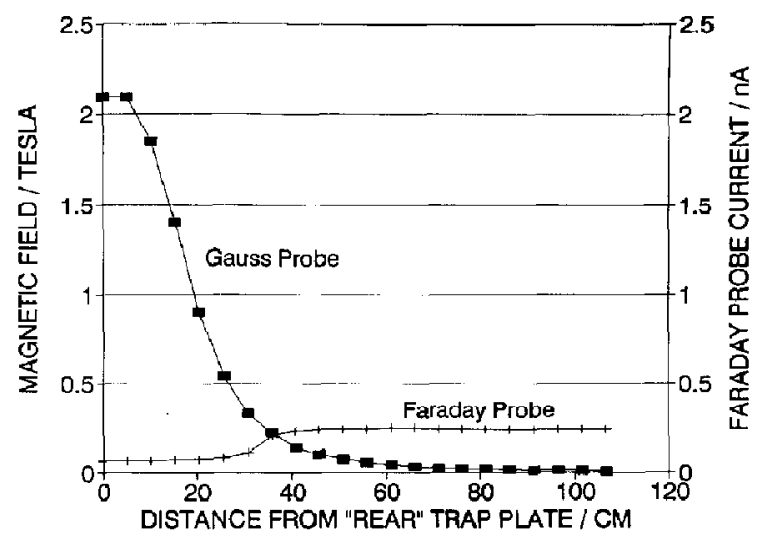

Figure 5. Magnetic field strength and Faraday probe current versus the distance from the rear trap plate. Lens voltages for these experiments were grid, $-825 \mathrm{~V}$; element $1,-898 \mathrm{~V}$; element $2,-684 \mathrm{~V}$; element $3,-674 \mathrm{~V}$; $\mathrm{CL}$, ground; flight tube, ground.

plate of the analyzer cell) increased approximately seven times in applying $-75 \mathrm{~V}$ to the $\mathrm{CL}$; this agrees surprisingly well with the results discussed in the previous paragraph obtained from ion signals detected by FT-ICR methods in the analyzer cell. An improvement in current of this approximate magnitude was seen over the entire distance from the CL to the analyzer cell. These results imply that the fringing magnetic fields may not play as large a part in reducing the GD beam intensity as in some other sources [18]. Second, as the ion beam was monitored closer to the analyzer cell, a decrease in signal was observed; this decrease occurred over the same region in which the magnetic field was sharply increasing, a fact that is not surprising. Finally, examining either Figure 5 or Figure 6 indicates that there was still a twofold to threefold loss in ion current arriving at the analyzer cell compared with that at the $\mathrm{CL}$, due solely to the fringing

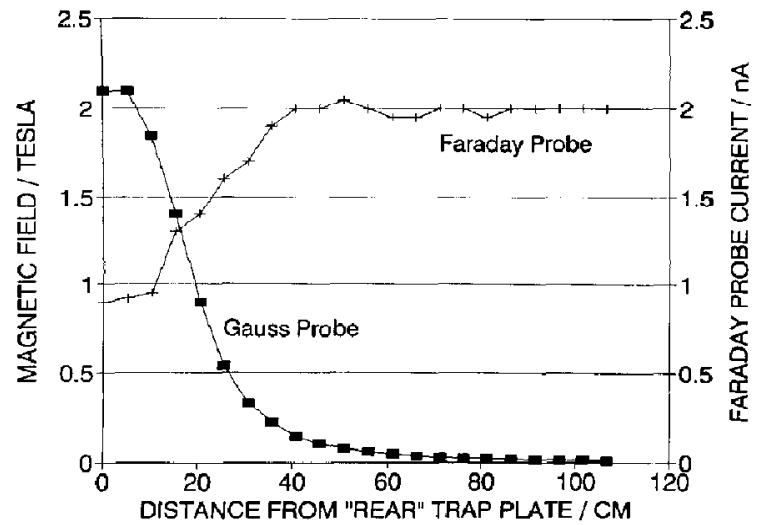

Figure 6. Magnetic field strength and Faraday probe current versus the distance from the rear trap plate. Lens voltages for these experiments were grid, $-825 \mathrm{~V}$; element $1,-898 \mathrm{~V}$; element $2,-684 \mathrm{~V}$; element $3,-674 \mathrm{~V} ; \mathrm{CL},-75 \mathrm{~V}$; flight tube, ground. 
fields of the magnet. Although this loss was not as high as first anticipated, an improvement in the number of ions transported to the cell will improve the overall sensitivity. To improve ion transport, an ion flight tube was built to carry the ions from just beyond the $C L$, through the magnetic field, and to the analyzer cell.

\section{Floating Conductance Limit with an Ion Elight Tube and an Ion Decelerator}

Kofel and McMahon [12] reported an ion flight tube design that is improved with respect to earlier electrostatic ion injection schemes [3] [which are also the basis of one commercial (Spectrospin AG, Fällanden, Switzerland) FT-ICR external ion injection instrument]. Our initial flight tube design was simpler than that of Kofel and McMahon [12] because we had no additional CL (even though this resulted in a higher ultimate pressure in the analyzer cell) and no transport lenses before the decelerator. In addition, the flight tube and first decelerator electrode were connected electrically in our system for convenience.

Similar to the manner in which the optimum CL voltage was determined, the ion signal was monitored in the ICR cell as a function of the negative bias applied to the flight tube and decelerator. The ion signal for the $\mathrm{H}_{2} \mathrm{O}^{+}$and $\mathrm{Ar}^{+}$species increased sharply until approximately $-25 \mathrm{~V}$ dc. Between -25 and $-175 \mathrm{~V}$ dc, the signal rose steadily; at $-175 \mathrm{~V} \mathrm{dc}$, the signal intensity reached a plateau and then decreased beyond $-200 \mathrm{~V} \mathrm{dc}$. In this manner a new set of optimum "test" conditions were established; these were $-825 \mathrm{~V}$ on the grid, $-898 \mathrm{~V}$ on lens $1,-684 \mathrm{~V}$ on lens $2,-674 \mathrm{~V}$ on lens $3,-75 \mathrm{~V}$ on the $\mathrm{CL}_{r}$ and $-175 \mathrm{~V}$ on the flight tube/decelerator.

Next, ion trajectories were simulated to show the effect of the flight tube/decelerator combination. Under our "test" conditions, the results shown in Figure 7 a were generated. Figure $7 \mathrm{a}$ illustrates how incorporation of both the flight tube and floating CL served to better collimate the ion beam than use of only the floating CL (see Figure 3). Similarly, trajectory calculations were made at the decelcrator/ICR cell interface (Figure $7 b$ ). These calculations were based on seven ions exiting the flight tube with $180 \mathrm{eV}$ of kinetic energy (the initial $5 \mathrm{eV}$ of kinetic energy imparted by the discharge plus the $175 \mathrm{eV}$ imparted by the flight tube). Because the decelerator is virtually in the center of the superconducting magnet, a constant magnetic field of $2.0 \mathrm{~T}$ was substituted for the magnetic field gradient used in Figures 3 and 7a. The ions were assigned trajecturies parallel to the injection axis, beginning $50.8 \mathrm{~mm}$ inside the flight tube.

Closer examination of all the data used to generate Figure $7 \mathrm{~b}$ shows that once the ions pass through the decelerator ring electrode and into the grounded housing, they lose all but their initial $5 \mathrm{eV}$ of kinetic energy; however, even after leaving the grounded section of the decelerator, the simulated ions still possess enough

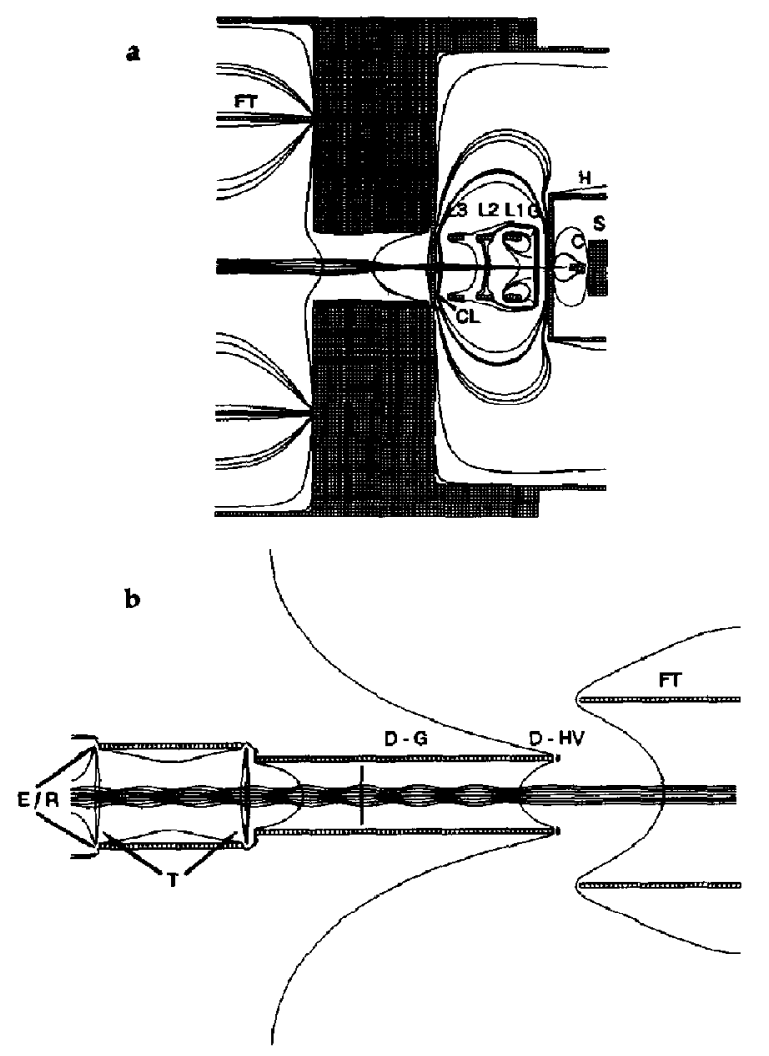

Figure 7. (a) SIMION trajectories calculated for 13 ions with 5-eV kinetic energy under the following conditions: housing $(\mathrm{H})$, ground; source (S), ground; cathode (C), $-0.5 \mathrm{~V}$; grid (G), -825 $\mathrm{V}$; element $1(\mathrm{~L} 1),-898 \mathrm{~V}$; element $2(\mathrm{~L} 2),-684 \mathrm{~V}$; element 3 (L3) $-674 \mathrm{~V}$; conductance limit (CL),$-75 \mathrm{~V}$; flight tube (FT), $-175 \mathrm{~V}$. (b) SIMION trajectories calculated for seven ions with $180-\mathrm{eV}$ kinetic energy under the following conditions: flight tube (FT), $-175 \mathrm{~V}$; decelerator high voltage (D-HV), - $175 \mathrm{~V}$; decelerator ground (D-G), ground; excite/receive ( $E / R)$, ground; trap (T), $+2 \mathrm{~V}$.

energy to overcome the $+2-\mathrm{V}$ trapping potential at both the front and rear plates. Experimentally, the ion beam will contain ions with a distribution of energies: some with energies too low to overcome the front trapping-plate voltage, which will therefore be turned around; some with energies very close to the trapping potentials; and some with sufficient energy to overcome the voltages on both the front and rear trapping plates and pass through the cell entirely. One additional means of trapping GD ions is collisions with the relatively high levels of argon in the cell. Ion-molecule cullisions occurring in the region between the trap plates reduce both the overall and $z$-axis kinetic energies of the ions and therefore increase the probability that they will be trapped.

The enhanced intensities of $\mathrm{H}_{2} \mathrm{O}^{+}$and $\mathrm{Ar}^{+}$detected in the analyzer cell when using the flight tube and decelerator indicated that these components definitely aided the transport of an increased population of 
GD-generated ions through the fringing magnetic fields. Improvements by a factor of $10-15$ in the detected ICR signals of these ions were seen, although for reasons not yet completely understood, analyte ion signals were improved very little. Similar to the Faraday probe experiments reported earlier, the total ion beam current was monitored along the injection axis with our new "test" conditions. Figure 8 illustrates how a virtually constant ion beam is present from the CL through the fringing magnetic field and into the ICR cell. Thus, the combination of a floating $C L$, flight tube, and decelerator increased the current of GD-generated ions reaching the analyzer cell by a factor of almost 20 (see Figure 5), with no apparent ion loss in the fringing magnetic field.

Other means of transporting ions through the fringing magnetic fields (such as the use of quadrupole rods [2]) could also be used in these GD/FT-ICR experiments. Because of their experimental simplicity, we have concentrated exclusively on the use of simple electrostatic lenses and flight tubes in our studies. Various means of enhancing the concentrations of analyte ions in the FT-ICR cell by selective ejection of unwanted ions $\left(\mathrm{Ar}^{+}, \mathrm{H}_{3} \mathrm{O}^{+}\right.$, and major substrate ions), particularly use of the SWIFT [19] technique, have not yet been attempted but will markedly improve the sensitivity of this method.

As GD mass spectrometry matures as a viable technique for elemental analysis, one of its formidable limitations-isobaric interferences-continues to be addressed through research using both high-mass resolving power and collision-induced dissociation of polyatomic interferences. It seems only appropriate that FT-ICR mass spectrometry, with its unique capabilities for providing both ultrahigh mass resolving power and collision-induced dissociation, should be at the forefront of this continuing research.

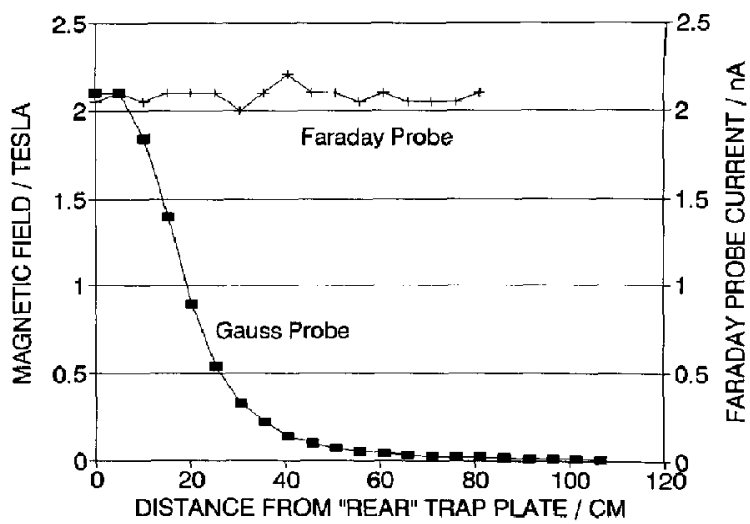

Figure 8. Magnetic field strength and Faraday probe current versus the distance from the rear trap plate. Lens voltages for these experiments were grid, $-825 \mathrm{~V}$; element $1,-898 \mathrm{~V}$; element $2,-684 \mathrm{~V}$; element $3,-674 \mathrm{~V} ; \mathrm{CL},-75 \mathrm{~V}$; flight tube, $-175 \mathrm{~V}$.

\section{Conclusions}

Addition of a floating $\mathrm{CL}$, a flight tube, and a decelerator just before the FT-ICR cell have improved the transport of ions from a GD source to the ICR analyzer cell by a factor of approximately 20. Residual pressures in the cell remain somewhat high (approximately 1.33 $\times 10^{-5} \mathrm{~Pa}$ ) due to the use of only two stages of differential pumping, and mass resolving powers are less than might be achieved with lower base pressures. Further improvements in both sensitivity and mass resolving power can be confidently predicted, poinling to FT-ICR mass spectrometry as the analysis method of choice for GD-generated ions.

\section{Acknowledgments}

This work was supported in part by the Office of Naval Research. We thank Drs. J. E. Bruce and K. R. Williams for helpful suggestions about both the research itself and the manuscript.

\section{References}

1. Cody, R. B.; Kinsinger, J. A. In Fourier Transform Mass Spectrometry: Evolution, Innowation, and Application, Vol. 359; ACS Symp. Series; Buchanan, M. V., Ed.; American Chemiçal Society: Washington, DC, 1987; p 59.

2. McIver, R. T. Jr.; Hunter, R. L.; Bowers, W. D. Int. J. Mass Spectrom. Ion Processes 1985, 64, 67

3. Kofel, P.; Allemann, M.; Kellerhals, H.; Wanczek, K. P. Int. J. Mass Spectrom. Ion Processes 1985, 65, 97.

4. Ijames, C. F.; Wilkins, C. L. J. Am. Soc. Mass Spectrom. 1990, 1,208

5. Grossmann, P.; Caravatti, P.; Dutsch, S.; Allemann, M.; Kellerhals, H. Lab. Pract. 1987, 36, 63.

6. Alford, J. M.; Williams, P. E.; Trevor, D. J.; Smalley, R. E. Int. 1. Mass Spectrom. Ion Processes 1986, 72, 33.

7. Barshick, C. M.; Eyler, J. R. I. Am. Suc. Mass Spectrum. 1992, 3, 122 .

8. Chapman, B. Glow Discharge Processes: Sputtering and Plasma Etching; Wiley: New York, 1980; p 77.

9. Watson, C. H.; Wronka, J.; Laukien, F. H.; Barshick, C. M.; Eyler, J. R., Anal. Chem., submitted.

10. Vieth, W.; Huneke, J. C. Spectrochim. Acta 1991, 46B, 137.

11. McIver, R. T. Jr. Int. I. Mass Spectrom. Ion Processes 1990, 98. 35 , and references therein.

12. Kofel, P.; McMahon, T. B. Int. J. Mass Spectrom. Ion Processes $1990,98,1$

13. Harris, F. J. Proc. IEEE 1978, 66, 51.

14. Buchanan, M. V.; Comisarow, M. B. In Fourier Transform Mass Spectrometry: Evolution, Imnovation, and Application, Vol. 359: ACS Symp. Series; Buchanan, M. V., Ed.; American Chemical Society: Washington, DC, 1987; $\mathrm{p} 1$.

15. Dahi, D. A.; Delmore, J. E. SIMION, Version 4.0, Idaho National Engineering Laboratory, EG \& G Idaho Inc., Idaho Falls, ID 83145.

16. Shoemaker, D. P.; Garland, C. W.; Steinfeld, J. I.; Nibler, J. W. Experiments in Physical Chemistry; McGraw-Hill: New York, 1981; $p 725$.

17. Long, G. L.; Winefordner, J. D. Anal. Chem. 1983, 46, 11.

18. Kebarle, P. In Techniques for the Study of Ion/Molecule Reactions; Farrar, J. M.; Saunders, W. H., Eds.; Wiley: New York, 1988: $\mathrm{p} 221$.

19. Marshall, A. B.; Wang, T. C.; Ricca, T. L. J. Am. Chem. Soc. 1985, 107, 7893 . 